\title{
Rebamipide-induced downregulation of phospholipase D inhibits inflammation and proliferation in gastric cancer cells
}

\author{
Dong Woo Kang ${ }^{1}$, Gyesik Min ${ }^{2}$, Do Yoon Park ${ }^{3}$, \\ Ki Whan Hong ${ }^{4}$ and Do Sik Min ${ }^{1,5}$ \\ ${ }^{1}$ Department of Molecular Biology \\ liferation of gastric cancer cells. In conclusion, re- \\ bamipide-induced downregulation of PLD may con- \\ tribute to the inhibition of inflammation and pro- \\ liferation in gastric cancer.
}

College of Natural Science

Pusan National University

Busan 609-735, Korea

${ }^{2}$ Department of Pharmaceutical Engineering

Jinju National University

Jinju 660-758, Korea

${ }^{3}$ Department of Pathology

College of Medicine

Pusan National University

Busan 609-739, Korea

${ }^{4}$ Medical Research Center for Ischemic Tissue Regeneration

Pusan National University

Yangsan 626-770, Korea

${ }^{5}$ Corresponding author: Tel, 82-51-510-3682;

Fax, 82-51-513-9258; E-mail, minds@ @usan.ac.kr

DOI 10.3858/emm.2010.42.8.056

Accepted 7 July 2010

Available Online 12 July 2010

Abbreviations: BrdU, 5-bromo-2'-deoxyuridine; PA, phosphatidic acid; PLD, phospholipase D; PtdBut, phosphatidylbutanol; q-RT$\mathrm{PCR}$, quantitative reverse transcriptase-polymerase chain reaction

\begin{abstract}
Rebamipide a gastroprotective drug, is clinically used for the treatment of gastric ulcers and gastritis, but its actions on gastric cancer are not clearly understood. Phospholipase D (PLD) is overexpressed in various types of cancer tissues and has been implicated as a critical factor in inflammation and carcinogenesis. However, whether rebamipide is involved in the regulation of PLD in gastric cancer cells is not known. In this study, we showed that rebamipide significantly suppressed the expression of both PLD1 and PLD2 at a transcriptional level in AGS and MKN-1 gastric cancer cells. Downregulation of PLD expression by rebamipide inhibited its enzymatic activity. In addition, rebamipide inhibited the transactivation of nuclear factor kappa B (NFKB), which increased PLD1 expression. Rebamipide or PLD knockdown significantly suppressed the expression of genes involved in inflammation and proliferation and inhibited the pro-
\end{abstract}

Keywords: cell proliferation; gene expression regulation, neoplastic; inflammation; phospholipase D; rebamipide; stomach neoplasms

\section{Introduction}

Rebamipide (2-[4-chlorobenzoylamino]-3-[2(1H)quinolinon-4-yl]propionic acid; OPC-12759) is a mucosal protective agent used for the treatment of gastritis and gastric ulcer (Arakawa et al., 1998). Rebamipide has been reported to act as an anti-inflammatory agent in both acute and chronic inflammation and has an inhibitory effect on proinflammatory cytokines (McCarthy et al., 2003). It exerts protective effect against gastric mucosal inflammation induced by Helicobacter pylori by inhibiting neutrophil function (Yoshida et al., 1996; Aihara et al., 1998; Arakawa et al., 2005). Main functions of rebamipide include mucus glycoprotein synthesis and stimulation of prostaglandin, inhibition of reactive oxygen species, inflammatory cytokines, and chemokines, and inhibition of neutrophil activation (Arakawa et al., 2005). Moreover, rebamipide has been reported to inhibit the growth of gastric cancer cells (Tarnawski et al., 2005; Tanigawa et al., 2007) and prevent dextran sulfate sodium-induced colitis in rats (Kishimoto et al., 2000). Although these studies shed some light on the actions of rebamipide, the exact targets and molecular mechanism of action of rebamipide in cancer cells are still unknown.

Phospholipase D (PLD) is a receptor-associated signaling enzyme catalyzing the hydrolysis of phosphatidylcholine (PC) to the lipid second messenger phosphatidic acid (PA) and choline in response to mitogenic signals (Exton et al., 2002). Two mammalian isozymes of PC-specific PLDs (PLD1 and PLD2) have been identified. Intracellular signaling mediated by PLD has been a target of interest in inflammation and tumor metastasis for more than 2 decades (Steed and Chow, 2001). PA activates nuclear factor kappa B $(\mathrm{NF} \kappa \mathrm{B})$, a bridge between inflammation and cancer, which increases the expression of diverse 
A
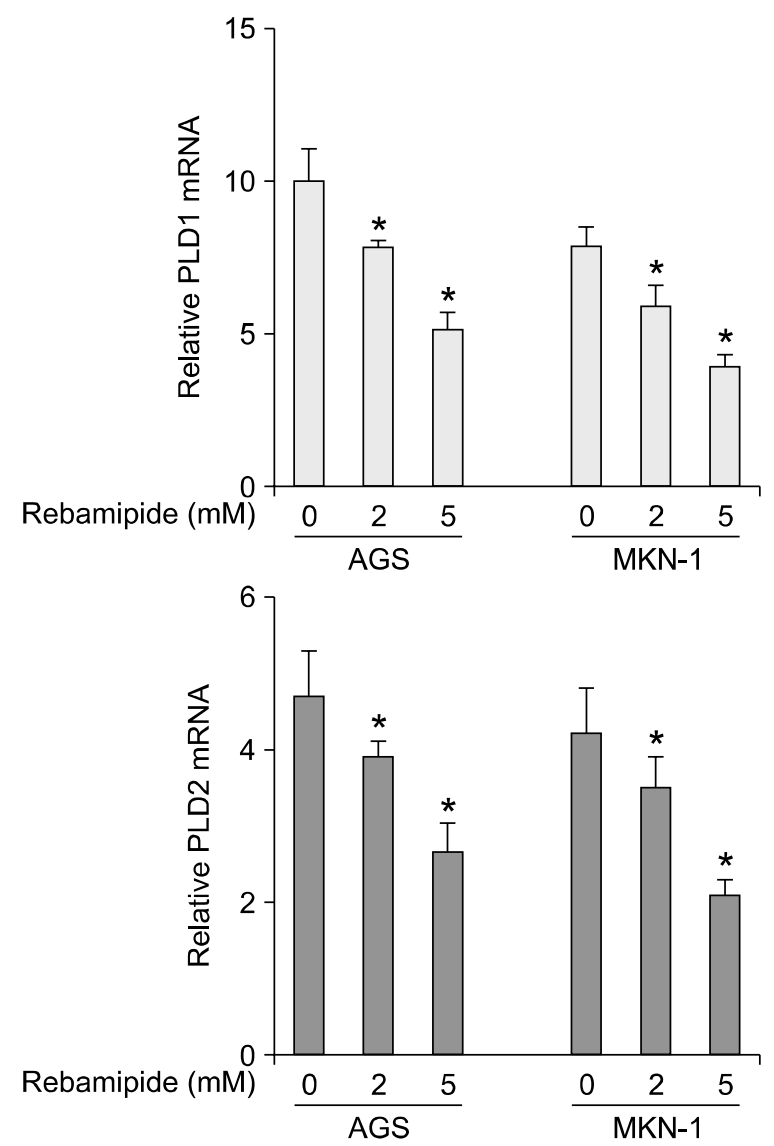

B
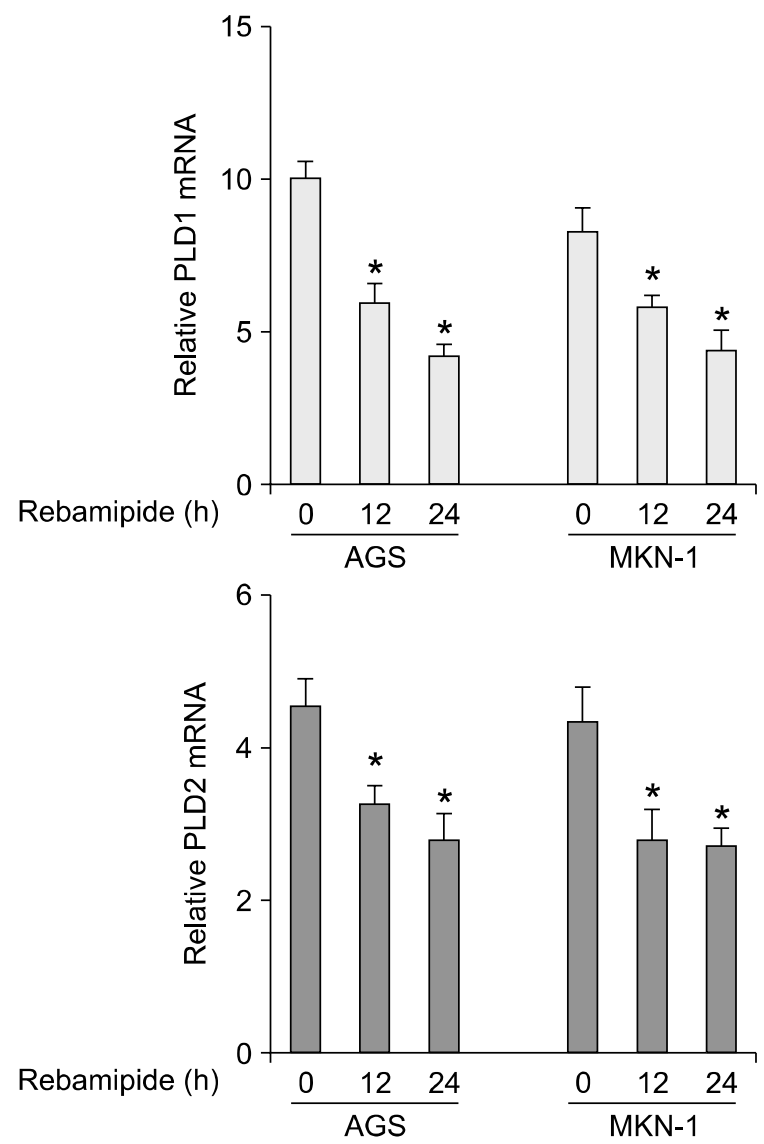

Figure 1. Rebamipide downregulates the transcriptional level of PLD isozymes in AGS and MKN-1 gastric cancer cells. (A) AGS and MKN-1 cells were treated with the indicated concentrations of rebamipide for $24 \mathrm{~h}$. The expression of PLD1 or PLD2 was analyzed by q-RT-PCR). Each value represents the mean \pm S.D. of the five independent experiments. ${ }^{*} P<0.05$ compared with non-treatment. (B) The cells were treated with $5 \mathrm{mM}$ rebamipide for the indicated times. The expression level of PLD1 or PLD2 was also analyzed by q-RT-PCR. Each value represents the mean \pm S.D. of the three independent experiments ${ }^{*} P<0.05$ compared with non-treatment.

genes involved in inflammation and carcinogenesis (Park et al., 2009; Grivennikov et al., 2010; Kang et al., 2010).

PLD activity is also elevated in cells transformed by a variety of transforming oncogenes, including v-Src, v-Ras, v-Fps, and v-Raf (Su et al., 2009). PLD is found to be upregulated at the protein and/or activity levels in various cancers, including breast, colon, gastric, kidney, and thyroid cancer. Overexpression of the PLD isozyme has been reported to induce anchorage-independent growth, tumor cell invasion, and formation of metastases in syngeneic mice (Min et al., 2001; Knoepp et al., 2008). Moreover, the activity was correlated with the nuclear grade in breast cancer (Uchida et al., 1997), tumor size in gastric carcinoma (Uchida et al., 1999), and nodal involvement and deeper invasion in colorectal carcinoma (Oshimoto et al., 2003). These studies provide compelling evidence that the elevated activity and expression of PLD observed in cancer are functionally linked with oncogenic signals and tumorigenesis. However, molecular mechanisms of the PLD gene expression have not been completely understood thus far.

In this study, we show for the first time that rebamipide inhibits cell proliferation and inflammation via downregulation of both PLD expression and activity in gastric cancer cells.

\section{Results}

\section{Rebamipide inhibits the expression of PLD isozymes in gastric cancer cells}

To examine whether or not rebamipide regulates PLD expression, we treated AGS and MKN-1 
A

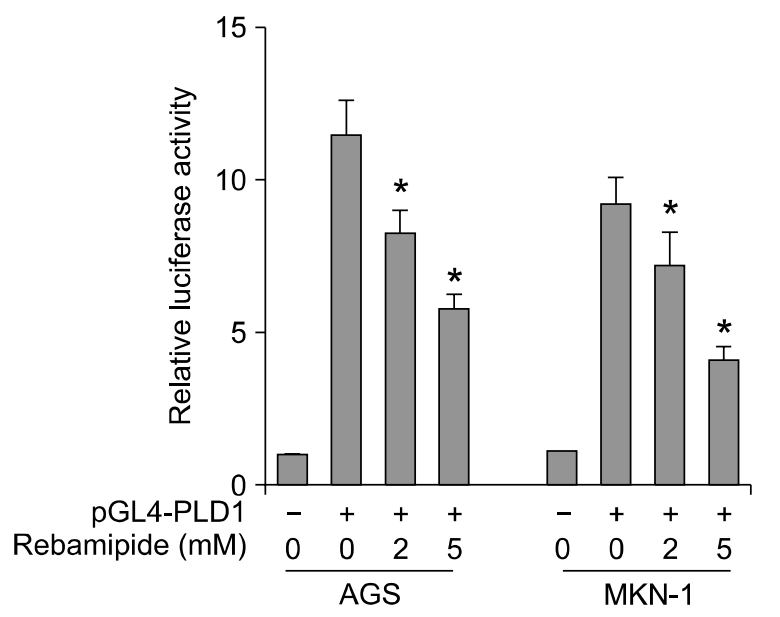

B

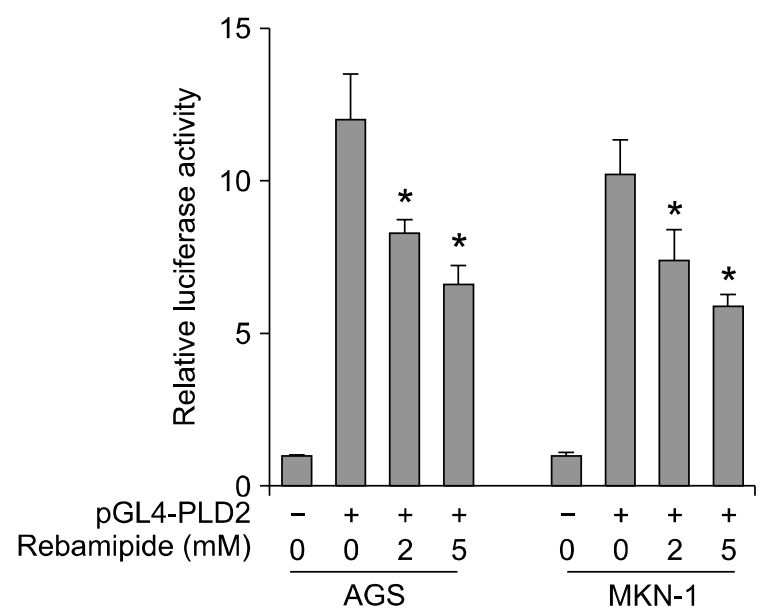

Figure 2. Rebamipide suppresses the promoter activity of PLD isozymes in gastric cancer cells. (A) AGS and MKN-1 cells were transiently transfected with PLD1 or PLD2 reporter constructs and treated with the indicated concentrations of rebamipide for $24 \mathrm{~h}$. The luciferase activity was subsequently measured. A renilla luciferase control vector was co-transfected to normalize the transfection efficiency. Each value represents the mean \pm S.D. of the five independent experiments. ${ }^{*} P<0.05$ versus non-treatment. (B) The cells were transiently transfected with PLD1 or PLD2 reporter constructs and treated with $5 \mathrm{mM}$ rebamipide for the indicated times. The luciferase activity was subsequently measured. ${ }^{*} P<0.05$ versus non-treatment.

gastric cancer cells with different concentrations of rebamipide. Treatment with rebamipide for $24 \mathrm{~h}$ decreased the expression level of PLD1 and PLD2 mRNA in a dose-dependent manner, with approximately $50 \%$ inhibition at $5 \mathrm{mM}$ as analyzed by quantitative reverse transcriptase-polymerase chain reaction (q-RT-PCR) (Figure 1A). Rebamipide also downregulated the expression level of both PLD1 and PLD2 in a time-dependent manner (Figure 1B). To further confirm whether rebamipide-induced PLD suppression is regulated at the transcriptional level, AGS or MKN-1 gastric cancer cells were transiently transfected with PLD1- or PLD2-luciferase reporter constructs and treated with rebamipide. As shown in Figures $2 \mathrm{~A}$ and $2 \mathrm{~B}$, rebamipide inhibited both PLD1 and PLD2 promoter activity in a dose-dependent manner. It decreased the promoter activities of both PLD isozymes with similar inhibitory potency in AGS and MKN-1 gastric cancer cells. Next, we examined whether or not rebamipide inhibits the level of the PLD protein. Immunoblot analysis indicated that rebamipide-induced decrease in PLD mRNA levels caused a significant decrease in the corresponding levels of PLD1 protein in a doseand time-dependent manner (Figures $3 \mathrm{~A}$ and $3 \mathrm{~B}$ ). Both AGS and MKN-1 gastric cancer cells predominantly expressed PLD1 protein. Dose and time kinetics of rebamipide-induced suppression of the PLD1 protein showed a pattern similar to that of the transcriptional expression. Taken together, these results suggest that the expression of PLD isozymes was downregulated by rebamipide at both transcriptional and posttranscriptional levels.
A

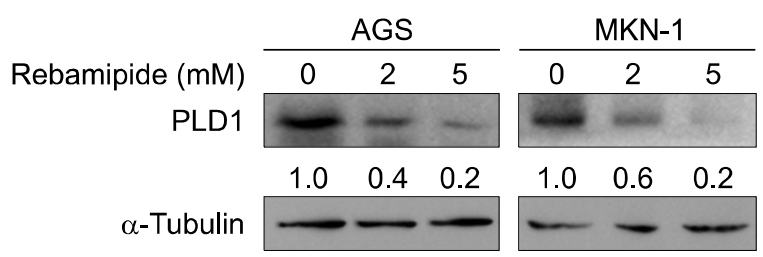

B

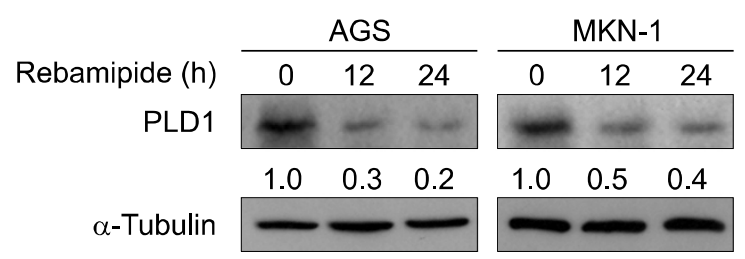

Figure 3. Rebamipide suppresses the expression of PLD1 protein in AGS and MKN-1 gastric cancer cells. (A) AGS and MKN-1 cells were treated with the indicated concentrations of rebamipide for $24 \mathrm{~h}$. (B) AGS and MKN-1 cells were treated with rebamipide $(5 \mathrm{mM})$ for the indicated times. The cell lysates were analyzed by western blot using an antibody to PLD. The level of PLD1 expression was determined by densitometer analysis. The data are representative of results obtained from three independent experiments. 


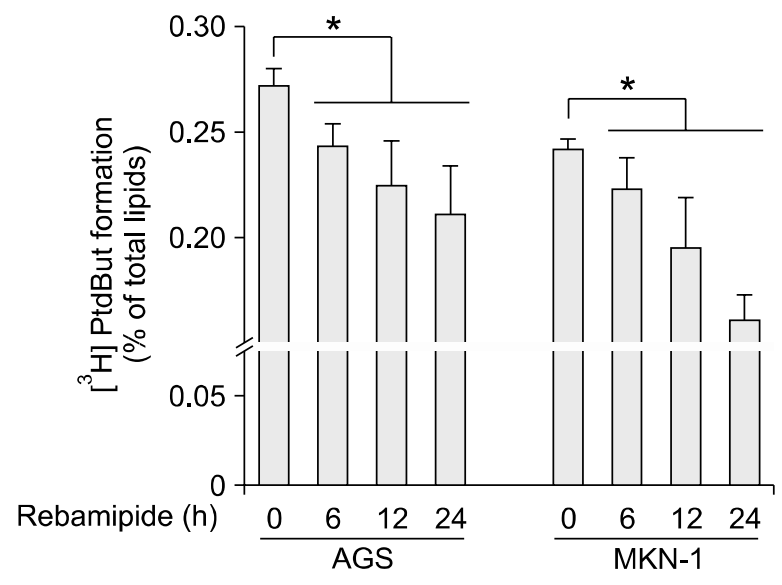

Figure 4. Rebamipide inhibits PLD activity in gastric cancer cells. AGS and MKN-1 cells were labeled with $\left[{ }^{3} \mathrm{H}\right]$ myristate for $12 \mathrm{~h}$, treated with 5 $\mathrm{mM}$ of rebamipide for the indicated times after which the PLD activity was measured. Each value represents the mean \pm S.D. of three independent experiments. ${ }^{*} P<0.05$ versus non-treatment.

\section{Rebamipide inhibits PLD activity in gastric cancer cells}

We examined whether rebamipide-induced suppression of PLD1 decreases its enzymatic activity. Treatment with rebamipide inhibited PLD activity in a time-dependent manner in AGS and MKN-1 gastric cancer cells (Figure 4). Moreover, rebamipide inhibited PLD activity stimulated by phorbol myristate acetate (PMA), which is known as a PLD activator (data not shown). These data show that rebamipide-induced suppression of PLD expression leads to a decrease in the PLD activity.

\section{Rebamipide suppresses PLD1 expression via inhibition of the transcriptional activity of NFKB}

We attempted to investigate the molecular mechanism underlying rebamipide-induced PLD suppression. Recently, we have reported that PMA selectively induces PLD1 expression via NFKB (Kang et al., 2008). Ectopic expression of NFKB (p65) enhanced the promoter activity, protein expression, and enzymatic activity of PLD1, but did not significantly affect these activities of PLD2 in HCT116 colorectal cancer cells (Kang et al., 2008). Two NFKB binding sites present on the PLD1 promoter were responsible for the PMA-induced PLD1 expression (Kang et al., 2008). We found that NFKB also enhanced PLD1 expression but not PLD2 in AGS and MKN-1 gastric cancer cells (Figure 5A). Therefore, we examined whether rebamipide affects the transcriptional activity of $\mathrm{NF}_{K B}$ in AGS cells. As shown in Figure 5B, rebamipide at a concentration of 2 or $5 \mathrm{mM}$ significantly inhibited the transactivation of $N F \kappa B$ in
AGS and MKN-1 cells. Moreover, rebamipide suppressed PMA-induced PLD1 promoter activity (Figure $5 \mathrm{C}$ ). These data suggest that rebamipide may suppress PLD1 expression via the inhibition of NFKB transactivation and inhibit PLD2 expression via a mechanism independent of $N F \kappa B$ transactivation.

\section{Rebamipide-induced PLD suppression inhibits the expression of genes involved in inflammation and proliferation in gastric cancer cells}

We examined whether rebamipide affects the expression of genes involved in inflammation, proliferation, and invasion in gastric cancer cells. q-RT-PCR indicated that treatment with rebamipide significantly suppressed the expression of proinflammatory genes, interleukin-6 (IL-6), IL-8, cyclooxygenase-2 (COX-2), and nitric oxide synthase 2 (NOS2) (Figure 6A). Moreover, rebamipide inhibited the expression of c-Myc and cyclin D1, which are involved in cell proliferation, and matrix metalloproteinase-2 (MMP-2) and MMP-9, which play an important role in invasion of cancer cells. Knockdown of both PLD1 and PLD2 significantly suppressed the expression levels of those genes (Figure $6 B$ ). Thus, these results suggest that rebamipide may suppress the expression of genes involved in inflammation, proliferation, and invasion by inhibiting PLD expression in gastric cancer cells.

\section{Rebamipide-induced PLD downregulation inhibits the proliferation of gastric cancer cells}

We further investigated the biological significance of rebamipide-induced PLD downregulation. The viability of MKN-1 gastric cancer cells was examined by treatment with rebamipide and measured by the MTT assay. Rebamipide inhibited the cell viability in a dose-dependent manner (Figure 7A). Moreover, depletion of both PLD1 and PLD2 using siRNAs led to decreased the cell viability (Figure 7B). Further, using 5-bromo-2'-deoxyuridine (BrdU) assay, we found that rebamipide inhibited the proliferation of MKN-1 cells and knockdown of both PLD1 and PLD2 significantly inhibited the proliferation of the gastric cancer cells (Figures $7 \mathrm{C}$ and 7D). These data suggest that the inhibitory effect of rebamipide on cell proliferation is mediated at least by rebamipide-induced PLD suppression.

\section{Discussion}

In this study, we showed for the first time that rebamipide downregulates the expression and enzy- 
A

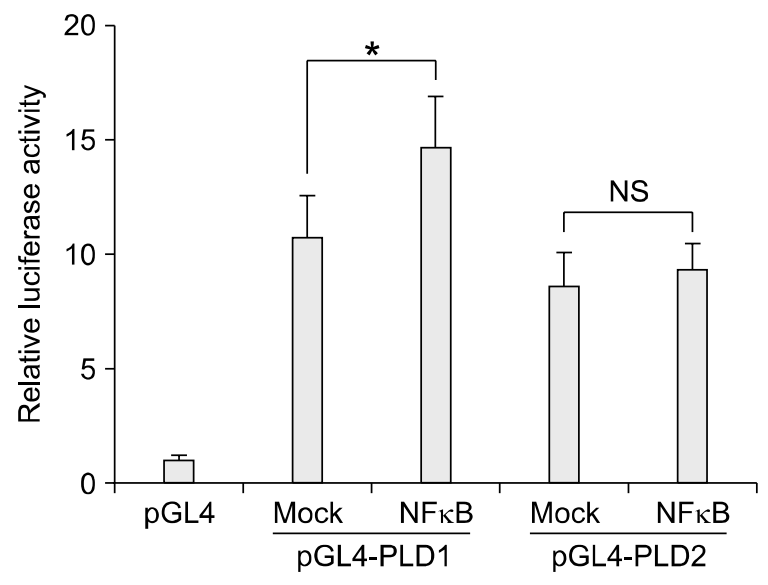

C

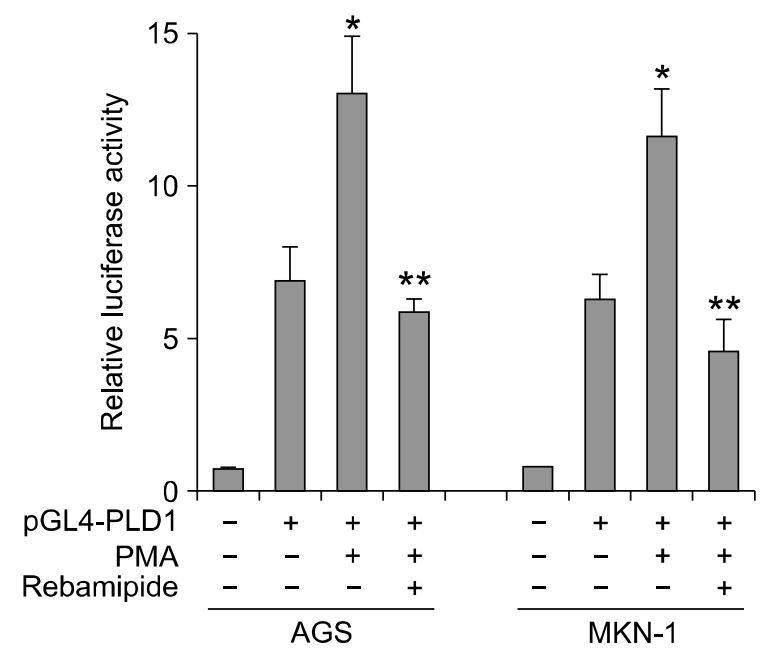

matic activity of PLD and subsequently inhibits inflammation and proliferation of gastric cancer cells. Rebamipide is a mucosal protective drug that accelerates the healing of gastritis and gastric ulcers and is widely used as a prophylactic agent to overcome the gastric adverse effects of nonsteroidal antiinflammatory drugs (Yamasaki et al., $1987,1989)$. This agent is known to stimulate prostaglandin production and mucus secretion, which play a role in the mucosal defense mechanism of the stomach (Kleine et al., 1993). Rebamipide has also been reported to inhibit the infiltration of inflammatory cells, generation of free radicals, and production of IL-8 thus exerting a potent anti-inflammatory effect (Watanabe et al., 1998; Kim et al., 2000; Hiratsuka et al., 2005; Sakurai et al., 2005). However, the action of this drug in cancer cells has not been clearly understood. Elevated expression and activity of
B

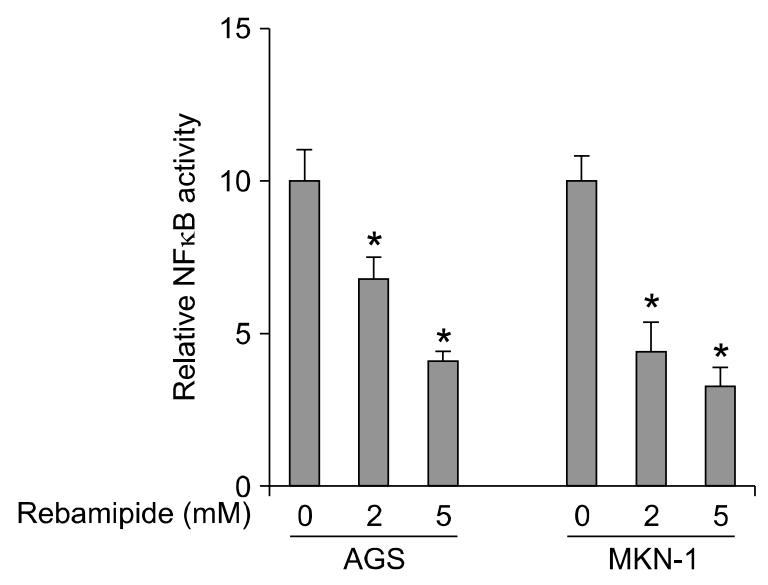

Figure 5. Rebamipide suppresses the promoter activity of PLD via inhibition of the transcriptional activity of NFKB in gastric cancer cells. (A) AGS and MKN-1 cells were co-transfected with pGL4-PLD and NFKB (p65) and the luciferase activity was subsequently measured. Each value represents the mean \pm S.D. of three independent experiments. ${ }^{*} P$

$<0.05$ versus vehicle for pGL4-PLD1. (B) The cells were transfected with the NFKB-dependent reporter plasmid pGL2-3X NFKB for $20 \mathrm{~h}$, treated with the indicated concentrations of rebamipide, and the luciferase activity was then measured. ${ }^{*} P<0.05$ versus non-treatment. (C) After AGS and MKN-1 cells were transiently transfected with pGL4-PLD1, the cells were pretreated with rebamipide $(5 \mathrm{mM})$ and treated with PMA (50 nM) for $20 \mathrm{~h} .{ }^{*} P<0.05$ versus non-treatment; ${ }^{* *} P<0.05$ versus PMA treatment.

PLD has been reported in a variety of human cancer tissues, including the breast, gastric, kidney, and colon (Su et al., 2009).

Overexpression of PLD isozymes has been reported to induce anchorage-independent growth, tumor cell invasion, and formation of metastases in syngeneic mice (Min et al., 2001; Knoepp et al., 2008). Elevated expression and activity of PLD in human cancers is likely a critical aspect of tumorigenesis that promotes cell proliferation and suppresses the inherent apoptotic pathways that prevent cancer. Thus, PLD plays an important role in cancer progression, and PLD could be a target for cancer therapy. Therefore, a strategy that aims to block the effect of PLD will decrease the expression and activity of PLD, break down a tumor-promoting loop, and thereby reduce tumor growth. PLD-generated PA induces acute inflammation both in vitro and in vivo (Lim et al., 2003). 
A

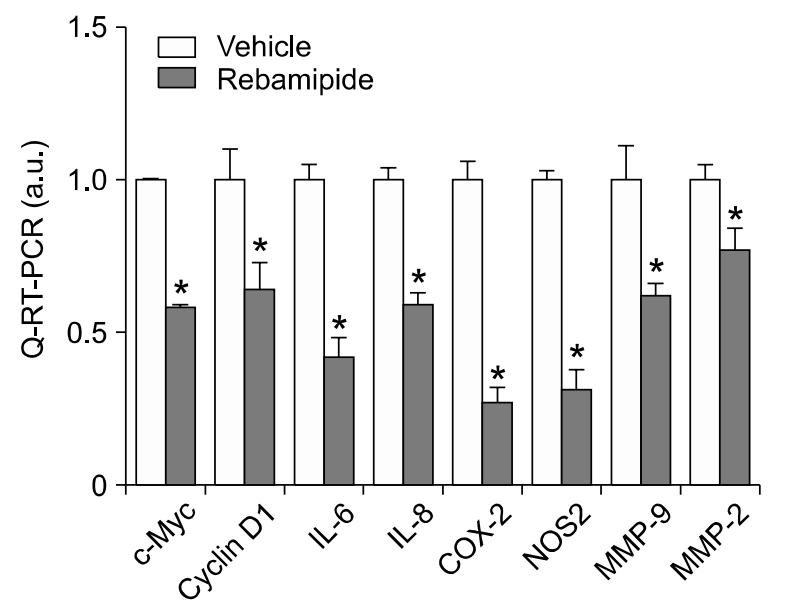

B

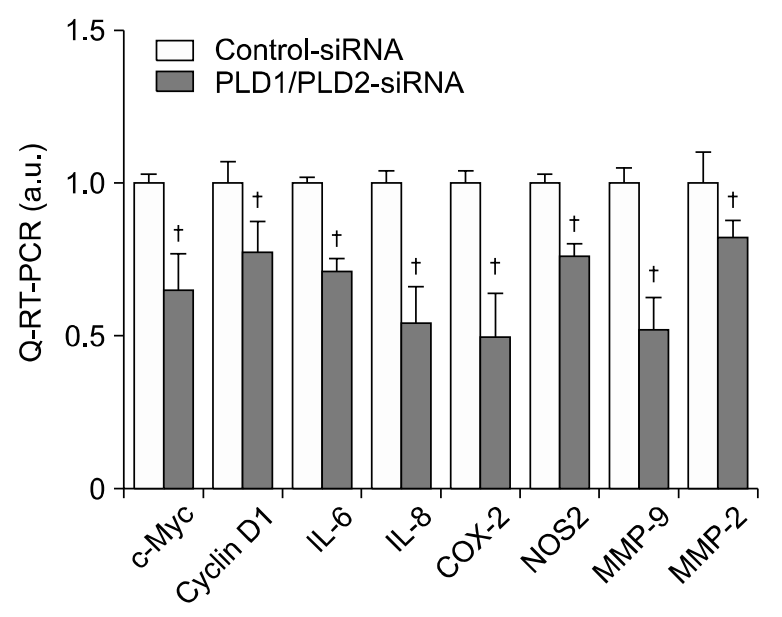

PA enhances the production of the proinflammatory cytokines and their mediators and facilitates the initiation of the host inflammatory response. Therefore, it is suggested that an anti-PA strategy or inhibition of PLD activity will contribute to the treatment of inflammatory diseases. Recently, we have reported that triptolide suppressed the proliferation of MDA-MB-231 breast cancer cells via downregulation of the expression of both PLD isozymes (Kang et al., 2009). This natural product used in traditional Chinese medicine for centuries, has a myriad of therapeutic uses against inflammation and autoimmune disease (Qiu and Kao, 2003).

In the current study, we found that rebamipide suppressed the expression of both PLD1 and PLD2 at the transcriptional level in gastric cancer cells. Moreover, rebamipide also inhibited PLD activity. Recently, we have reported that a tumor
Figure 6. Rebamipide-induced downregulation of PLD inhibits the expression of inflammatory and proliferation genes of gastric cancer cells. (A) MKN-1 cells were treated with or without 5 $\mathrm{mM}$ rebamipide for $24 \mathrm{~h}$. The expression of inflammatory and proliferation genes was also analyzed by q-RT-PCR. ${ }^{*} P<0.05$ versus vehicle. (B) The cells were transfected with siRNAs for control or PLD1 and PLD2 for $48 \mathrm{~h}$. The expression of genes involved in inflammation, proliferation, or invasion was also analyzed by q-RT-PCR. Each value represents the mean \pm S.D. of five independent experiments. ${ }^{P} P<0.05$ versus control siRNA.

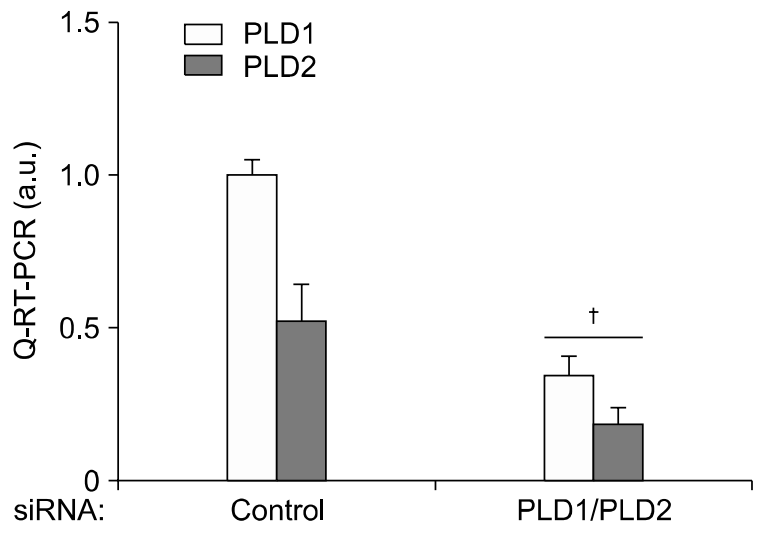

promoter signal such as PMA selectively stimulates PLD1 expression by increasing the binding of NFKB to the PLD1 promoter (Kang et al., 2008). NFKB did not affect PLD2 expression (Kang et al., 2008). We found that rebamipide inhibited the transactivation of $\mathrm{NFKB}$ in $\mathrm{AGS}$ and $\mathrm{MKN}-1$ gastric cancer cells. Thus, it is suggested that remabipide-mediated PLD1 suppression may be due to the inhibition of $N F \kappa B$ activity by remabipide. However, it is likely that rebamipide inhibits PLD2 expression via a pathway distinct from that of PLD1 since NFKB is not responsible for PLD2 expression. To date, the lack of potent and isoform-selective inhibitors has limited the progress in defining the cellular roles of PLD. Recently, isoform-selective PLD inhibitors have been developed (Scott et al., 2009) and may facilitate a better understanding of the biological roles played by the respective PLD isozymes. Rebamipide inhibits the 
A

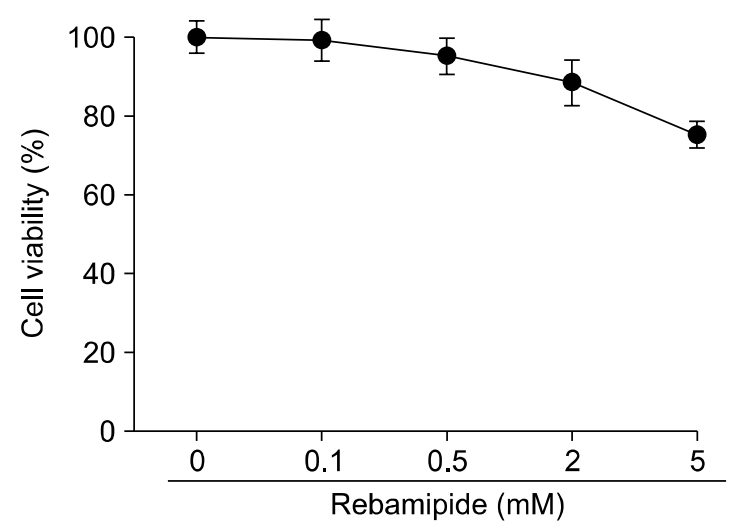

B

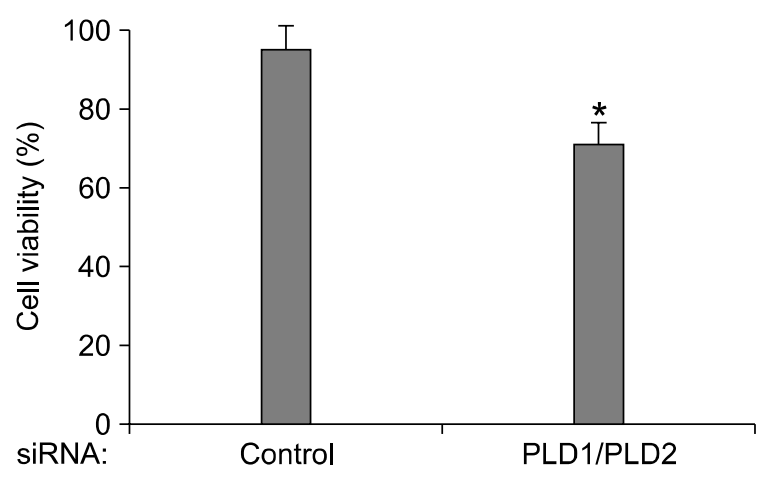

C
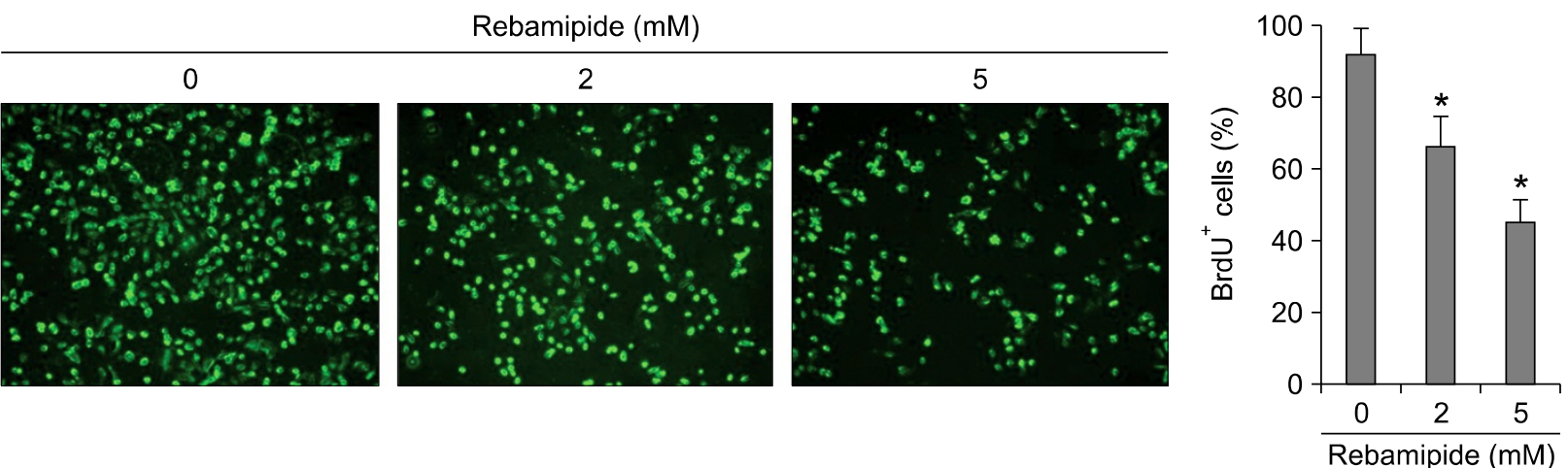

D
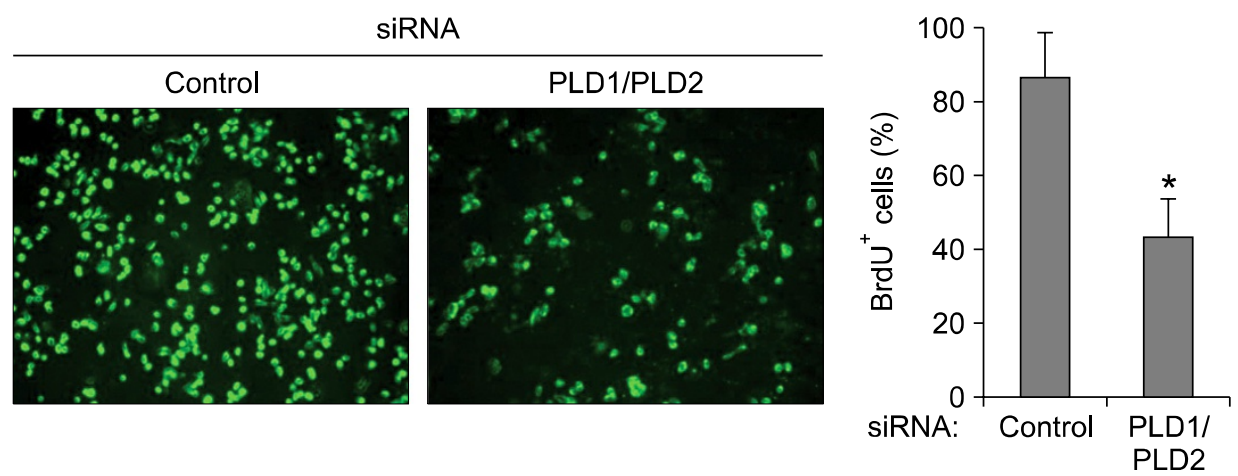

Figure 7. Rebamipide-induced suppression of PLD inhibits the proliferation of gastric cancer cells. (A) MKN-1 cells were treated with the indicated concentrations of rebamipide for $24 \mathrm{~h}$. The cell viability was then measured using the MTT assay. (B) The cells were transfected with both siRNAs for PLD1 and PLD2 for $48 \mathrm{~h}$. The cell viability was measured using the same methods. Each value represents the mean \pm S.D. of three independent experiments. ${ }^{*} P<0.05$ versus control siRNA. (C) After MKN-1 cells were treated with the indicated concentrations of rebamipide for $24 \mathrm{~h}$, proliferation of the cells was analyzed by BrdU incorporation (green). Scale bar, $100 \mu \mathrm{m}$. Quantification of the percentage of BrdU-positive (BrdU ${ }^{+}$) cells in total living cells of control. ${ }^{*} P<0.05$ versus control siRNA. (D) After MKN-1 cells were co-transfected with both siRNAs for PLD1 and PLD2, proliferation of the cells was analyzed by BrdU incorporation (green). Scale bar, $100 \mu \mathrm{m}$. Quantification of the percentage of BrdU-positive (BrdU ${ }^{+}$) cells in total living cells of control-siRNA. ${ }^{*} P$ $<0.05$ versus control-siRNA.

expression of both PLD1 and PLD2 in gastric cancer cells. The effect of rebamipide on gastric cancer has not been explored to date except for 2 studies (Tarnawski et al., 2005; Tanigawa et al., 2007). Rebamipide has been reported to inhibit gastric cancer cell growth by downregulation of 
survivin and Aurora-B (Tarnawski et al., 2005).

We found that rebamipide inhibited the expression of genes involved in inflammation, proliferation, and invasion in gastric cancer cells. Downregulation of PLD with specific siRNAs preceded a significant inhibition of MKN-1 gastric cancer cell proliferation reflected by reduced viability and BrdU incorporation. This finding underscores the essential role of PLD in cell proliferation. In this study, rebamipide induced inhibition of gastric cancer cell proliferation and PLD expression at 2 or $5 \mathrm{mM}$ of concentration.

In summary, we have identified PLD as a potential therapeutic target of rebamipide. Rebamipide can be used as a dual inhibitor for PLD1 and PLD2 expression. Rebamipide is used in Japan, Korea, China, Philippines, and other Asian countries for treatment of gastritis, which in chronic stages may be associated with intestinal metaplasia and gastric cancer; therefore, our findings have important clinical implications. Overall, the present study provides a rationale for further testing of anticancer properties of rebamipide.

\section{Methods}

\section{Cell lines and compounds}

Human gastric cancer cells (AGS and MKN-1) were purchased from ATCC (Manassas, VA) and were maintained in Dulbecco's modified Eagle's medium (DMEM) with 10\% heat-inactivated fetal bovine serum with $1 \%$ antibiotic-antimycotic (Gibco BRL, Grand Island, NY) and $15 \mathrm{mmol} / \mathrm{L}$ HEPES ( $\mathrm{pH}$ 7.4). Rebamipide was kindly provided by Otsuka Pharmaceutical Co., Ltd (Tokyo, Japan).

\section{Plasmids and small interfering RNA}

The pCMV NFKB (p65) and pGL2-3X NFKB plasmids containing a triple tandem repeat of an NFKB-binding motif were used. The human PLD1 (pGL4-PLD1 Luc) and PLD2 (pGL4-PLD2 Luc) promoter reporter plasmids contained $1.9 \mathrm{~kb}$ and $2.6 \mathrm{~kb}$, respectively, of the upstream $5^{\prime}$-flanking DNA linked to luciferase reporter genes and have been described elsewhere (Kang et al., 2008). SiRNAs of control, PLD1, and PLD2 were purchased from Dharmacon Research Inc. (Lafayette, CO). The siRNA sequences for the PLDs were as follows: PLD1 (1571 to 1591), AAGGUGGGACGACAAUGAGCA; PLD2 (1378 to 1396), ACAUAAAGGUGAUGCGUCA. An oligonucleotide corresponding to nucleotides $695-715$ of the firefly luciferase was used as negative control.

\section{Transient transfection and reporter gene assay}

Cells were grown to $50-60 \%$ confluence. The plasmid or siRNA was transiently transfected into gastric cancer cells using the transfection agents Lipofectamine Plus (Invitrogen, Carlsbad, CA) or Polyethylenimine (Sigma, MO), following the manufacturer's instructions. For the luciferase reporter assay, the cells were seeded in 24-well plates and transiently transfected with $300 \mathrm{ng}$ of promoter constructs and $30 \mathrm{ng}$ of $\mathrm{pRL}-\mathrm{TK}$ (internal control). For the NFKB transactivation assay, pGL2-3X NFKB, which contained 3 tandem repeats of the NFKB binding motif, was used. The activities of firefly and renilla luciferase in the cellular extracts were measured using the Dual-Luciferase Assay kit (Promega, WI) according to the manufacturer's instructions.

\section{Western blotting}

Cell lysates were analyzed by immunoblot. Enhanced chemiluminescence was used for signal detection. Anti- $\alpha$-tubulin was obtained from Santa Cruz Biotechnology (Santa Cruz, CA). Rabbit polyclonal anti-PLD antibody that recognizes both PLD1 and PLD2 was generated as previously described (Min et al., 2001).

\section{PLD activity assay}

PLD activity was assessed by measuring the formation of $\left[{ }^{3} \mathrm{H}\right]$ phosphatidylbutanol, the product of PLD-mediated transphosphatidylation, in the presence of 1-butanol. AGS and $\mathrm{MKN}-1$ gastric cancer cells were seeded in 6-well plates and serum-starved in the presence of $3 \mu \mathrm{Ci}$ of $\left[{ }^{3} \mathrm{H}\right]$ myristic acid $/ \mathrm{ml}$. After overnight starvation, the cells were washed 3 times with $5 \mathrm{ml}$ phosphate-buffered saline (PBS) and pre-equilibrated in serum-free DMEM for $1 \mathrm{~h}$. For the final $10 \mathrm{~min}$ of pre-incubation, $0.3 \% 1$-butanol was added. At the end of the pre-incubation, cells were treated with rebamipide for the indicated times. The extraction and characterization of lipids by thin-layer chromatography were performed as previously described (Ahn et al., 2003).

\section{RNA isolation and quantitative RT-PCR}

Total RNA was isolated from cells using the TRIzol reagent (Invitrogen). First-strand cDNA was synthesized using AMV-RTase (Promega), and real-time RT-PCRs were performed using the CFX96 real-time system equipped on a C1000TM Thermal Cycler (Bio-Rad, Laboratories Inc.). After the initial step at $95^{\circ} \mathrm{C}$ for $5 \mathrm{~min}$, we performed 40 cycles at $95^{\circ} \mathrm{C} 30 \mathrm{~s}, 60^{\circ} \mathrm{C}$ for $1 \mathrm{~s}$, and $72^{\circ} \mathrm{C}$ for $2 \mathrm{~s}$. Reaction samples $(20 \mu \mathrm{l})$ included $2 \mu \mathrm{l}$ of cDNA, target-specific primers, and the Fast EvaGreen qPCR Master Mix (Bio-Rad, Laboratories Inc.). The temperature range for the analysis of the melting curves was from $55^{\circ} \mathrm{C}$ to $99^{\circ} \mathrm{C}$ over $30 \mathrm{~s}$. The quality and quantity of the templates were normalized to GAPDH. Reactions were performed in triplicate, and final results were calculated using a relative standard curve. The q-RT-PCR forward and reverse, respectively, primer sequences for GAPDH were 5'-GTGGTCTCCTCTGACTTCAAC-3' and 5'-TCTCTTCCTCTTGTGCTCTTG-3'; for PLD1, 5'-TGTCGTGATACCACTTCTGCCA-3' and 5'-AGCATTTCGAGCTGCTGTTGAA-3'; for PLD2, 5'-CATCCAGGCCATTCTGCAC-3' and 5'-GTGCTTCCGCAGACTCAAGG-3'; for c-Myc, 5'-TCCAGCTTGTACCTGCAGGATCTGA-3' and 5'-CCTCCAGCA- 
GAAGGTGATCCAGACT-3'; for cyclin D1, 5'-CGCCTCACACGCTTCCTCTC-3' and 5'-CACСTCCTCCTCCTCCTCTTCC-3'; for IL-6, 5'-TAGTCCTTCCTACCCCAATTTCC-3' and 5'-TTGGTCCTTAGCCACTCCTTC-3'; for IL-8, 5'-CACCGGAAGGAACCATCTCACT-3' and 5'-TCAGCCCTCTTCAAAAACTTCTCC-3'; for COX-2, 5'-TGAGCATCTACGGTTTGCTG-3' and 5'-TGCTTGTCTGGAACAACTGC-3'; for NOS2, 5'-TGCCAGATGGCAGCATCAGA-3' and 5'-TTTCCAGGCCCATTCTCCTGC-3'; for MMP-2, 5'-CAGTGACGGAAAGATGTGGTGTG-3' and 5'-AGACGGAAGTTCTTGGTGTAGGTG-3'; and for MMP-9, 5'-CTGGGCAAGGGCGTCGTG-3' and 5'-GGTCGTCGGTGTCGTAGTTGG-3'.

\section{Cell growth assay}

We seeded $2 \times 10^{4}$ cells into each well of 24 -well plates. The medium was replaced with new medium containing defined doses of rebamipide $24 \mathrm{~h}$ later. Six days after treatment, the medium was changed with phenol red-free medium containing $500 \mu \mathrm{g} / \mathrm{ml} \quad 3$-(4,5-dimethylthiazol-2-yl)-2,5-diphenyl tetrazolium bromide (MTT, Sigma). The MTT-containing medium was removed after $3 \mathrm{~h}$ of incubation. The incorporated dye was dissolved in 100 $\mu \mathrm{l} /$ well DMSO, and the plates were read at a wavelength of $540 \mathrm{~nm}$ using an ELISA reader. Absorbance in the treated cells was expressed as percentage of the control. Three separate experiments were performed.

\section{5-Bromo-2'-deoxyuridine labeling and detection}

BrdU labeling was performed using the BrdU labeling and detection kit I (Roche Applied Science), following the manufacturer's protocol. In brief, cells were grown in an 12-well chamber and BrdU-labeling medium was added to cells and incubated at $37^{\circ} \mathrm{C}$ for $3 \mathrm{~h}$. Cells were washed once with $1 \times$ PBS followed by ethanol fixation for $20 \mathrm{~min}$ at $-20^{\circ} \mathrm{C}$. After washing cells, anti-BrdU reagent was added for $30 \mathrm{~min}$ at $37^{\circ} \mathrm{C}$. For fluorescence detection, anti-mouse immunoglobulin fluorescein was added and incubated for $30 \mathrm{~min}$. Cells were mounted with anti-fading mounting medium and then visualized under an fluorescence microscope (Axiovert 200M, Zwiss, Germany).

\section{Acknowledgements}

This work was supported for two years by Pusan National University Research Grant. We are most grateful to Dr. Dai Hyun Yu (Otsuka Pharmaceutical Co. Ltd. Otsuka International Asia Arab Division, Korea) for his helpful suggestions and generous comments.

\section{References}

Ahn BH, Kim SY, Kim EH, Choi KS, Kwon TK, Lee YH, Chang JS, Kim MS, Jo YH, Min DS. Transmodulation between Phospholipase D and c-Src Enhances Cell Proliferation. Mol Cell Biol 2003;23:3103-15

Aihara M, Azuma A, Takizawa H, Tsuchimoto D, Funakoshi Y, Shindo Y, Ohmoto Y, Imagawa K, Kikuchi M, Mukaida N, Matsushima K. Molecular analysis of suppression of interleukin-8 production by rebamipide in Helicobacter pylori-stimulated gastric cancer cell lines. Dig Dis Sci 1998;43:174S-80S

Arakawa T, Kobayashi K, Yoshikawa T, Tarnawski A. Rebamipide: overview of its mechanisms of action and efficacy in mucosal protection and ulcer healing. Dig Dis Sci 1998;43;5S-13S

Arakawa T, Higuchi K, Fujiwara Y, Watanabe T, Tominaga K, Sasaki E, Oshitani N, Yoshikawa T, Tarnawski AS. 15th anniversary of rebamipide: looking ahead to the new mechanisms and new applications. Dig Dis Sci 2005;50:S3-11

Exton JH. Phospholipase D-structure, regulation and function. Rev Physiol Biochem Pharmacol 2002;144:1-94

Grivennikov SI, Greten FR, Karin M. Immunity, inflammation, and cancer. Cell 2010;140:883-99

Hiratsuka T, Futagami S, Shindo T, Hamamoto T, Ueki N, Suzuki K, Shinji Y, Kusunoki M, Shinoki K, Wada K, Miyake K, Gudis K, Tsukui T, Sakamoto C. Rebamipide reduces indomethacin-induced gastric injury in mice via downregulation of ICAM-1 expression. Dig Dis Sci 2005;50: S84-9

Kang DW, Park MH, Lee YJ, Kim HS, Kwon TK, Park WS, Min DS. Phorbol ester upregulates phospholipase D1 but not phospholipase D2 expression through a PKC/Ras/ERK/ NFkappaB-dependent pathway and enhances matrix metalloproteinase- 9 secretion in colon cancer cells. J Biol Chem 2008;283:4094-104

Kang DW, Lee JY, Oh DH, Park SY, Woo TM, Kim MK, Park $\mathrm{MH}$, Jang $\mathrm{YH}$, Min DS. Triptolide-induced suppression of phospholipase $D$ expression inhibits proliferation of MDA-MB-231 breast cancer cells. Exp Mol Med. 2009;41: 678-85

Kang DW, Park MH, Lee YJ, Kim HS, Lindsley CW, Brown $H A$, Min DS. Autoregulation of phospholipase D activity is coupled to selective induction of phospholipase D1 expression to promote invasion of breast cancer cells. Int J Cancer 2010; In press

Kim H, Seo JY, Kim KH. Inhibition of lipid peroxidation, NF-kappaB activation and IL-8 production by rebamipide in Helicobacter pylori-stimulated gastric epithelial cells. Dig Dis Sci 2000;45:621-8

Kishimoto S, Haruma K, Tari A, Sakurai K, Nakano M, Nakagawa Y. Rebamipide, an antiulcer drug, prevents DSS-induced colitis formation in rats. Dig Dis Sci 2000; 45:1608-16

Kleine A, Kluge S, Peskar BM. Stimulation of prostaglandin biosynthesis mediates gastroprotective effect of rebamipide in rats. Dig Dis Sci 1993;38:1441-9

Knoepp SM, Chahal MS, Xie Y, Zhang Z, Brauner DJ, Hallman MA, Robinson SA, Han S, Imai M, Tomlinson S, Meier KE. Effects of active and inactive phospholipase D2 on signal transduction, adhesion, migration, invasion, and metastasis in EL4 lymphoma cells. Mol Pharmacol 2008;74:574-84

Lim HK, Choi YA, Park W, Lee T, Ryu SH, Kim SY, Kim JR, Kim JH, Baek SH. Phosphatidic acid regulates systemic 
inflammatory responses by modulating the Akt-mammalian target of rapamycin-p70 S6 kinase 1 pathway. J Biol Chem 2003;278:45117-27

McCarthy J, O'Mahony L, O'Callaghan L, Sheil B, Vaughan EE, Fitzsimons N, Fitzgibbon J, O'Sullivan GC, Kiely B, Collins JK, Shanahan F. Double blind, placebo controlled trial of two probiotic strains in interleukin 10 knockout mice and mechanistic link with cytokine balance. Gut 2003;52:975-80

Min DS, Kwon TK, Park WS, Chang JS, Park SK, Ahn BH, Ryoo ZY, Lee YH, Lee YS, Rhie DJ, Yoon SH, Hahn SJ, Kim MS, Jo YH. Neoplastic transformation and tumorigenesis associated with overexpression of phospholipase D isozymes in cultured murine fibroblasts. Carcinogenesis 2001;22:1641-7

Oshimoto H, Okamura S, Yoshida M, Mori M. Increased activity and expression of phospholipase D2 in human colorectal cancer. Oncol Res 2003;14:31-7

Park MH, Ahn BH, Hong YK, Min do S. Overexpression of phospholipase $\mathrm{D}$ enhances matrix metalloproteinase-2 expression and glioma cell invasion via protein kinase $C$ and protein kinase A/NF-kappaB/Sp1-mediated signaling pathways. Carcinogenesis 2009;30:356-65

Qiu D, Kao PN. Immunosuppressive and anti-inflammatory mechanisms of triptolide, the principal active diterpenoid from the Chinese medicinal herb Tripterygium wilfordii Hook. f. Drugs R D 2003;4:1-18

Sakurai K, Osaka T, Yamasaki K. Rebamipide reduces recurrence of experimental gastric ulcers: role of free radicals and neutrophils. Dig Dis Sci 2005;50:S90-6

Scott SA, Selvy PE, Buck JR, Cho HP, Criswell TL, Thomas $\mathrm{AL}$, Armstrong MD, Arteaga CL, Lindsley CW, Brown HA. Design of isoform-selective phospholipase $D$ inhibitors that modulate cancer cell invasiveness. Nat Chem Biol 2009; 5:108-17
Steed PM, Chow AH. Intracellular signaling by phospholipase $D$ as a therapeutic target. Curr Pharm Biotechnol 2001;2:241-56

Su W, Chen Q, Frohman MA. Targeting phospholipase D with small-molecule inhibitors as a potential therapeutic approach for cancer metastasis. Future Oncol 2009;5: 1477-86

Tanigawa T, Pai R, Arakawa T, Tarnawski AS. Rebamipide inhibits gastric cancer cell growth. Dig Dis Sci 2007;52:240-7

Tarnawski A, Pai R, Chiou SK, Chai J, Chu EC. Rebamipide inhibits gastric cancer growth by targeting survivin and Aurora-B. Biochem Biophys Res Commun 2005;334:207-12

Uchida N, Okamura S, Nagamachi Y, Yamashita S. Increased phospholipase D activity in human breast cancer. J Cancer Res Clin Oncol 1997;123:280-5

Uchida N, Okamura S, Kuwano H. Phospholipase D activity in human gastric carcinoma. Anticancer Res 1999;19:671-5

Watanabe S, Wang XE, Hirose M, Osaka T, Tanaka H, Sato N. Rebamipide prevented delay of wound repair induced by hydrogen peroxide and suppressed apoptosis of gastric epithelial cells in vitro. Dig Dis Sci 1998;43:107S-12S

Yamasaki K, Kanbe T, Chijiwa T, Ishiyama H, Morita S. Gastric mucosal protection by OPC-12759, a novel antiulcer compound in the rat. Eur J Pharmacol 1987;142:23-9

Yamasaki K, Ishiyama H, Imaizumi T, Kanbe T, Yabuuchi Y. Effect of OPC-12795, a novel antiulcer agent, on chronic and acute experimental gastric ulcer, and gastric secretion in rats. Jpn J Pharmacol 1989;49:441-8

Yoshida N, Yoshikawa T, linuma S, Arai M, Takenaka S, Sakamoto K, Miyajima T, Nakamura Y, Yagi N, Naito Y, Mukai $\mathrm{F}$, Kondo M. Rebamipide protects against activation of neutrophils by Helicobacter pylori. Dig Dis Sci 1996;41: 1139-44 